\title{
Interactive Effects of Joint Angle, Contraction State and Method on Estimates of Achilles Tendon Moment Arms
}

\author{
Florian Fath, ${ }^{1}$ Anthony J. Blazevich, ${ }^{2}$ Charlie M. Waugh, ${ }^{1}$ \\ Stuart C. Miller, ${ }^{1,3}$ and Thomas Korff ${ }^{1}$ \\ ${ }^{1}$ Brunel University; ${ }^{2}$ Edith Cowan University; ${ }^{3}$ Middlesex University
}

\begin{abstract}
The muscle-tendon moment arm is an important input parameter for musculoskeletal models. Moment arms change as a function of joint angle and contraction state and depend on the method being employed. The overall purpose was to gain insights into the interactive effects of joint angle, contraction state and method on the Achilles tendon moment arm using the center of rotation (COR) and the tendon excursion method (TE). Achilles tendon moment arms were obtained at rest $\left(\mathrm{TE}_{\text {rest }}, \mathrm{COR}_{\text {rest }}\right)$ and during a maximum voluntary contraction $\left(\mathrm{COR}_{\mathrm{MVC}}\right)$ at four angles. We found strong correlations between $\mathrm{TE}_{\text {rest }}$ and $\mathrm{COR}_{\mathrm{MVC}}$ for all angles $(.72 \leq r \leq .93)$ with Achilles tendon moment arms using $\mathrm{COR}_{\mathrm{MVC}}$ being $33-36 \%$ greater than those obtained from $\mathrm{TE}_{\text {rest }}$. The relationship between Achilles tendon moment arms and angle was similar across both methods and both levels of muscular contraction. Finally, Achilles tendon moment arms for $\mathrm{COR}_{\mathrm{MvC}}$ were 1-8\% greater than for $\mathrm{COR}_{\text {rest }}$.
\end{abstract}

Keywords: moment arm, ankle joint, tendon excursion, center of rotation

Muscle-tendon moment arms are important input parameters for musculoskeletal models. Achilles tendon moment arm $\left(\mathrm{MA}_{\mathrm{AT}}\right)$ has been estimated in vivo using both the tendon excursion (TE) $)^{1-3}$ and the center of rotation (COR) methods. ${ }^{4,5}$ Recently, $\mathrm{MA}_{\mathrm{AT}}$ magnitude was reported to be significantly smaller when the tendon excursion method was used compared with the center of rotation method. However, both methods correlated well across participants for a range of joint angles. ${ }^{6}$ Thus, the possibility exists that while $\mathrm{MA}_{\mathrm{AT}}$ estimates might differ between the methods, the joint-angle dependent changes in $\mathrm{MA}_{\mathrm{AT}}$ are relatively consistent. Furthermore, $\mathrm{MA}_{\mathrm{AT}}$ changes with the level of muscle contraction. ${ }^{4}$ However, contrary to the center of rotation method, the measurement of $\mathrm{MA}_{\mathrm{AT}}$ using the tendon excursion method during muscular contraction is associated with severe limitations. The tendon excursion method is based on

Florian Fath is with the Centre for Sports Medicine and Human Performance, Brunel University, London, UK. Anthony J. Blazevich is with the School of Exercise, Biomedical and Health Sciences, Edith Cowan University, Australia. Charlie M. Waugh is with the Centre for Sports Medicine and Human Performance, Brunel University, London, UK. Stuart C. Miller is with the Centre for Sports Medicine and Human Performance, Brunel University, London, UK, and with the School of Health and Social Science, Middlesex University, London, UK. Thomas Korff (Corresponding Author) is with the Centre for Sports Medicine and Human Performance, Brunel University, London, UK. the principle of virtual work 7,8 and therefore assumes that the work done by an external torque is equivalent to the virtual work done by the muscles and tendons. Implicit in this is the assumption that no energy is lost during a muscle contraction. Given that muscles and tendons store, release and dissipate elastic energy during muscle contractions, the principle of virtual work is violated, and this violation is likely to be more significant when large muscle forces are produced. Using the relationship between moment arms obtained from the tendon excursion method at rest and those obtained using the center of rotation method during a MVC might therefore be a more meaningful way of accounting for contractiondependent changes in moment arms derived from the tendon excursion method.

Therefore, the overall purpose of this study was to investigate the interactive effects of method, joint angle and contraction level on $\mathrm{MA}_{\mathrm{AT}}$ estimates. The specific aims were (1) to test the assumption that the $\mathrm{MA}_{\mathrm{AT}}$ estimated using the tendon excursion method at rest $\left(\mathrm{TE}_{\text {rest }}\right)$ would be related to estimates obtained using the center of rotation method during a maximum voluntary contraction $\left(\mathrm{COR}_{\mathrm{MVC}}\right)$ and (2) to test the assumption that joint angle-related changes in $\mathrm{MA}_{\mathrm{AT}}$ would be independent of method and contraction state.

\section{Methods}

With institutional ethical approval and after providing written informed consent, six healthy adults ( 4 men and 
2 women) participated in this study (age $=30 \pm 6 y$, stature $=1.76 \pm 0.11 \mathrm{~m}$, mass $=74 \pm 14 \mathrm{~kg}$ ).

$\mathrm{MA}_{\mathrm{AT}}$ about the right ankle joint was obtained using both the center of rotation (at rest and during MVC) and the tendon excursion (at rest) methods. For the center of rotation method, participants were asked to lie supine in a 3-Tesla magnetic resonance imaging scanner (Siemens Magnetom Trio syngo magnetic resonance 2004A) with their leg straight (ie, knee angle $=0^{\circ}$ ). The foot was securely fastened with two inelastic Velcro straps. Magnetic resonance images were taken during rest and MVC (sagittal scans, repetition time $=600[20] \mathrm{ms}$, echo time $=12$ [5] ms, 3 [1] excitations, 300-mm field of view, 2 [3]-mm slice thickness for rest and MVC [ ], respectively) at six different ankle positions $\left(60^{\circ}-135^{\circ}\right.$, in $15^{\circ}$ increments; $90^{\circ}=$ foot perpendicular to tibia). Using the magnetic resonance images, the center of rotation of the ankle joint, the line of action (of the Achilles tendon) and consequently the $\mathrm{MA}_{\mathrm{AT}}$ were determined during rest and MVC at ankle angles of $75^{\circ}, 90^{\circ}, 105^{\circ}$ and $120^{\circ}$ using the Reuleaux method as previously described by others in detail (Figure 1).4,9

For the tendon excursion method, participants were seated on an isokinetic dynamometer (Biodex System 3, Biodex Medical Systems, Inc., NY) with their right knee straight $\left(0^{\circ}\right)$ and a relative hip angle of $85^{\circ}$. The right foot was secured firmly to the dynamometer's footplate with the lateral malleolus aligned with the center of rotation of the dynamometer. The ankle was passively rotated through its range of motion by the dynamometer five consecutive times at $10^{\circ} \cdot \mathrm{s}^{-1}$. For all participants, the range of motion was greater than $75^{\circ}$ (dorsiflexion) and $120^{\circ}$ (plantar flexion). To determine tendon displacement, a 10-MHz B-mode, 40-mm linear ultrasound probe (Esoate Megas GPX, Genova, Italy) was placed over the muscletendon junction of the gastrocnemius medialis. Raw position data (sampled at $1 \mathrm{kHz}$ ) from the isokinetic dynamometer were low-pass filtered (4th-order Butterworth, zero-lag, $3.75 \mathrm{~Hz}$ cut-off). Ultrasound video data were sampled at $25 \mathrm{~Hz}$. The positions of the muscle-tendon

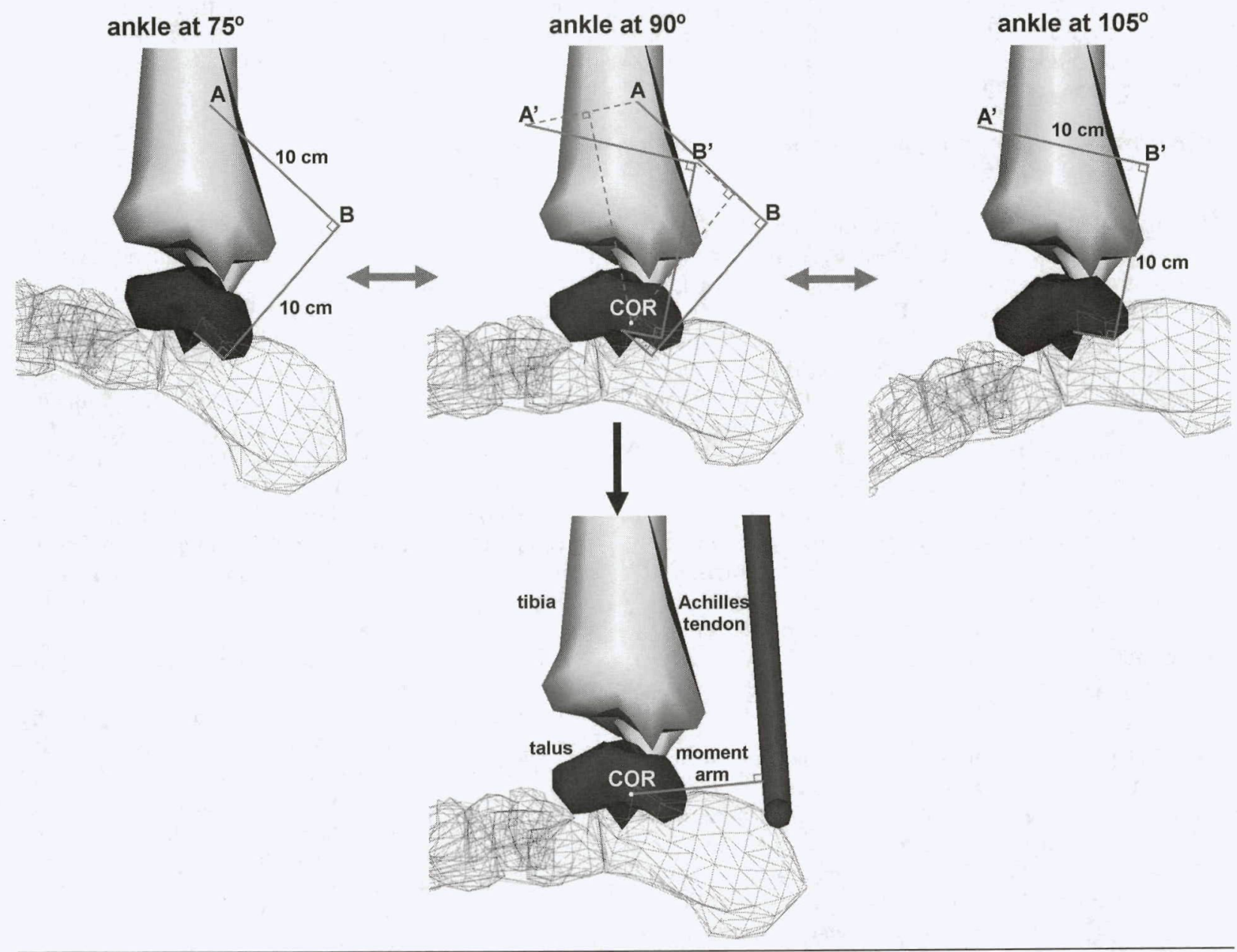

Figure 1 - Schematic illustration of the center of rotation method using the Reuleaux geometrical method to determine Achilles tendon moment arm (Reuleaux, 1875). Note. To determine the moment arm at $90^{\circ}$, for example, magnetic resonance scans were taken at $90 \pm 15^{\circ}$ and the center of rotation of the joint was subsequently determined. The tibia was assumed to be a constant throughout the joint rotation and the talus was the designated as the rotating segment. Achilles tendon moment arm at $90^{\circ}$ was defined as the perpendicular distance between the center of rotation of the ankle joint and the line of force (ie, the Achilles tendon). 
junction and the Achilles tendon were manually digitized, low-pass filtered (4th-order Butterworth, zerolag, $2.63 \mathrm{~Hz}$ cut-off) and down-sampled to $25 \mathrm{~Hz}$. The tendon and joint angular displacement data were plotted against joint angular displacement over the interval of $75^{\circ}$ and $120^{\circ}$, and approximated by fitting a 2 nd-order polynomial (mean $( \pm \mathrm{SD})$ coefficient of determination = $0.996 \pm 0.002$ ). To calculate the $\mathrm{MA}_{\mathrm{AT}}$, the polynomial was analytically differentiated at the four ankle angles of interest. $\mathrm{MA}_{\mathrm{AT}}$ measurements were analyzed three times at each angle for each method. The coefficient of variation was smaller than $5 \%$ for all conditions. More detailed descriptions of the experimental protocol and the derivation of $\mathrm{MA}_{\mathrm{AT}}$ are published elsewhere. ${ }^{6}$

To determine the relationship between $\mathrm{TE}_{\text {rest }}$ and $\mathrm{COR}_{\mathrm{MVC}}$, four Pearson's product-moment correlations were performed (one at each angle). To test if $\mathrm{MA}_{\mathrm{AT}}$ obtained using $\mathrm{TE}_{\text {rest }}, \mathrm{COR}_{\text {rest }}$ and $\mathrm{COR}_{\mathrm{MVC}}$ would change similarly as a function of ankle angle, and, to determine if this change was independent of muscular contraction level, a repeated-measures ANOVA $\left(3 \times 3, \mathrm{TE}_{\mathrm{rest}}\right.$, $\mathrm{COR}_{\text {rest }}, \mathrm{COR}_{\mathrm{MVC}}$ at ankle angles of $75^{\circ}, 90^{\circ}$ and $105^{\circ}$ ) was performed. Here, we tested for a method $\times$ angle interaction. To test this effect independent of differences in $\mathrm{MA}_{\mathrm{AT}}$ magnitude, all $\mathrm{MA}_{\mathrm{AT}}$ values were normalized by the $\mathrm{MA}_{\mathrm{AT}}$ obtained at $120^{\circ}$ for the corresponding condition. To further illustrate the changes of $\mathrm{MA}_{\mathrm{AT}}$ across angles and method, we quantified the correlations between $\mathrm{MA}_{\mathrm{AT}}$ and ankle angle for each participant and each method. To provide more specific information about the $\mathrm{COR}_{\text {rest }}-\mathrm{COR}_{\mathrm{MVC}}$ comparison, we also report percentage differences for all angles. Statistical significance was accepted at an alpha of .05.

\section{Results}

The correlation coefficients quantifying the relationship between $\mathrm{TE}_{\text {rest }}-\mathrm{COR}_{\mathrm{MVC}}$ ranged between .72 and .93 (Table 1). The repeated-measures ANOVA revealed no method $\times$ angle interaction $(F(4,20)=0.769 ; P=.558)$ (Figure 2). The mean correlations between $\mathrm{MA}_{\mathrm{AT}}$ and ankle angle were $1 \pm 0.00, .91 \pm 0.10$ and $0.95 \pm 0.08$ for $\mathrm{TE}_{\mathrm{rest}}, \mathrm{COR}_{\text {rest }}$ and $\mathrm{COR}_{\mathrm{MVC}}$, respectively. MA magnitudes were larger at the $120^{\circ}$ than the $75^{\circ}$ ankle angle with mean differences of $24.5 \pm 12.2 \%, 19.9 \pm$ $6.3 \%$ and $24.3 \pm 7.3 \%$ for $\mathrm{TE}_{\text {rest }}, \mathrm{COR}_{\text {rest }}$ and $\mathrm{COR}_{\mathrm{MVC}}$, respectively. When comparing $\mathrm{COR}_{\text {rest }}$ and $\mathrm{COR}_{\mathrm{MVC}}$, the percentage differences in $\mathrm{MA}_{\mathrm{AT}}( \pm \mathrm{SD})$ were $0.8 \pm 6.5 \%$, $3.7 \pm 2.8 \%, 5.5 \pm 6.4 \%$ and $7.9 \pm 6 \%$ at ankle angles of $75^{\circ}, 90^{\circ}, 105^{\circ}$ and $120^{\circ}$, respectively.

\section{Discussion}

The first aim of this study was to directly compare $\mathrm{MA}_{\mathrm{AT}}$ obtained from $\mathrm{TE}_{\text {rest }}$ and $\mathrm{COR}_{\mathrm{MVC}}$. We found strong correlations between $\mathrm{MA}_{\mathrm{AT}}$ obtained from $\mathrm{TE}_{\text {rest }}$ and $\mathrm{COR}_{\mathrm{MVC}}$ across a range of ankle angles with $\mathrm{MA}_{\mathrm{AT}}$ values obtained from $\mathrm{TA}_{\text {rest }}$ being significantly smaller. These results extend previous findings by demonstrating that $\mathrm{MA}_{\mathrm{AT}}$ obtained using the center of rotation method at MVC and tendon excursion method at rest are well correlated and therefore independent of contraction state. ${ }^{6}$ The significantly smaller $\mathrm{MA}_{\mathrm{AT}}$ 's obtained from the tendon excursion method can be explained by the viscoelastic nature of the tendon. As the Achilles tendon becomes more slack during the passive plantar flexion rotation, the displacement of muscle tendon junction for a given joint rotation is reduced which leads to an underestimation of $\mathrm{MA}_{\mathrm{AT}}$. The second aim was to test the hypothesis that $\mathrm{MA}_{\mathrm{AT}}$ would change as a function of ankle angle independently of the method of $\mathrm{MA}_{\mathrm{AT}}$ estimation. In conformity with this hypothesis, we found (1) no angle $\times$ method interaction and (2) similar moment arm-joint angle correlations for all experimental conditions (Figure 2). Our results extend previous findings by demonstrating that the relationship between $\mathrm{MA}_{\mathrm{AT}}$ and joint angle is not only independent of muscular contraction level but also of the method used.

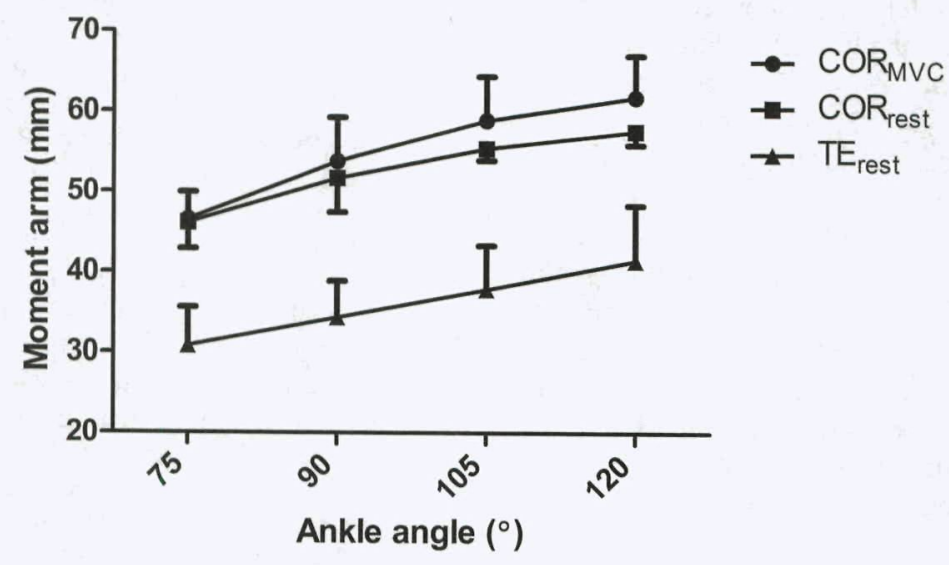

Figure 2 - Achilles tendon moment arm measurements (mean \pm SD) at four different ankle angles obtained from the tendon excursion method at rest $\left(\mathrm{TE}_{\mathrm{rest}}\right)$ and from the center of rotations method at both rest $\left(\mathrm{COR}_{\text {rest }}\right)$ and during a maximum isometric contraction $\left(\mathrm{COR}_{\mathrm{MVC}}\right)$. Note. $90^{\circ}$ ankle angle refers to the foot being perpendicular to the tibia. 


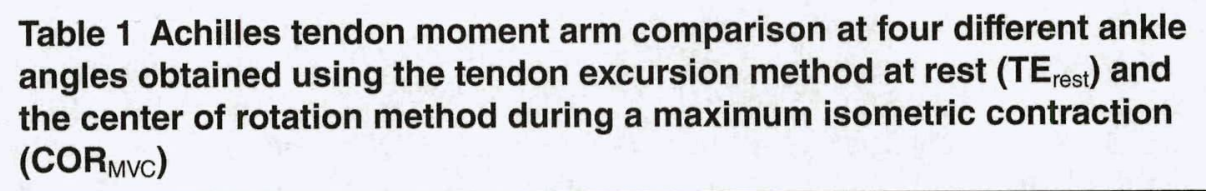

\begin{tabular}{|c|c|c|c|c|c|c|}
\hline \multirow[b]{2}{*}{ Ankle Angle } & \multirow[b]{2}{*}{$T E_{\text {rest }}$} & \multicolumn{2}{|c|}{ Moment arm (mm; mean $\pm \mathrm{SD})$} & \multicolumn{3}{|c|}{$\mathrm{TE}_{\text {rest }}-\mathrm{COR}_{\mathrm{MVc}}$} \\
\hline & & $\mathrm{COR}_{\text {rest }}$ & $\mathrm{COR}_{\mathrm{MVC}}$ & $r$ & $\boldsymbol{R}^{2}$ & $P$ \\
\hline $75^{\circ}$ & $30.8 \pm 6.7$ & $46.1 \pm 3.3$ & $46.5 \pm 3.4$ & .72 & .51 & .11 \\
\hline $90^{\circ}$ & $34.3 \pm 4.5$ & $51.7 \pm 4.3$ & $53.8 \pm 5.5$ & .93 & .86 & .01 \\
\hline $105^{\circ}$ & $37.9 \pm 5.4$ & $55.4 \pm 1.5$ & $58.5 \pm 5.5$ & .77 & .59 & .07 \\
\hline $120^{\circ}$ & $41.1 \pm 6.9$ & $56.7 \pm 2.4$ & $61.8 \pm 5.2$ & .78 & .61 & .06 \\
\hline
\end{tabular}

Another interesting aspect of our data is the difference in $\mathrm{MA}_{\mathrm{AT}}$ between $\mathrm{COR}_{\mathrm{rest}}$ and $\mathrm{COR}_{\mathrm{MVC}}$. This difference ranged between 1 and $8 \%$, which is considerably smaller than that reported by Maganaris et al, ${ }^{4}$ who found differences between 22 and $27 \%$. This discrepancy can potentially be explained by the different knee angle used by Maganaris et al $\left(90^{\circ}\right)$ compared with the present investigation $\left(0^{\circ}\right)$. We adopted a knee angle of $0^{\circ}$ in an attempt to minimize the influence of tendon slack, which has the potential to introduce errors into the $\mathrm{MA}_{\mathrm{AT}}$ estimation when using the tendon excursion method. ${ }^{7}$ The increase in $\mathrm{MA}_{\mathrm{AT}}$ during $\mathrm{MVC}$ compared with rest can be explained by a shift of the Achilles tendon away from the joint center, due to a thickening of the plantar flexor muscles. ${ }^{4}$ This shift is possibly smaller in magnitude when the knee is fully extended compared with a more flexed position. Support for this speculation comes from Riemann et al, ${ }^{10}$ who demonstrated that muscle stiffness of the gastrocnemius medialis is greater during full knee extension compared with more flexed positions. A direct consequence of the greater stiffness could be a reduction of Achilles tendon movement during MVC and therefore a reduced increase in $\mathrm{MA}_{\mathrm{AT}}$ during $\mathrm{MVC}$ when compared with rest. Our results, in combination with those of Maganaris et al, ${ }^{4}$ let us speculate that there is an interaction between knee angle, $\mathrm{MA}_{\mathrm{AT}}$ and plantar flexor contraction level. Future research should be conducted to specifically test this hypothesis.

The present findings have specific implications for musculoskeletal modeling. Our descriptive results can be used as guidance for modelers to account for the dependence of $\mathrm{MA}_{\mathrm{AT}}$ on ankle angle and contraction level. However, it is important to consider the within-group variability observed in our participants. The somewhat large standard deviations reported here indicate that the interaction between ankle angle, muscular contraction level and $\mathrm{MA}_{\mathrm{AT}}$ can differ between individuals. This variability should be taken into consideration by performing appropriate sensitivity analyses.

\section{Acknowledgments}

This study was supported by a grant from the Engineering and Physical Sciences Research Council, UK (EPSRC Reference: EP/E013007/1).

\section{References}

1. Lee SSM, Piazza SJ. Inversion-eversion moment arms of gastrocnemius and tibialis anterior measured in vivo. J Biomech. 2008;41(16):3366-3370 10.1016/j. jbiomech.2008.09.029. PubMed doi:10.1016/j.jbiomech.2008.09.029

2. Lee SSM, Piazza SJ. Built for speed: musculoskeletal structure and sprinting ability. $J$ Exp Biol. 2009;212(Pt 22):3700-3707 10.1242/jeb.031096. PubMed doi:10.1242/ jeb.031096

3. Maganaris $\mathrm{CN}$. Force-length characteristics of the in vivo human gastrocnemius muscle. Clin Anat. 2003;16(3):215223 10.1002/ca.10064. PubMed doi:10.1002/ca.10064

4. Maganaris CN, Baltzopoulos V, Sargeant AJ. Changes in Achilles tendon moment arm from rest to maximum isometric plantarflexion: in vivo observations in man. $J$ Physiol. 1998;510(3):977-985 10.1111/j.1469-7793.1998.977bj.x. PubMed doi:10.1111/j.1469-7793.1998.977bj.x

5. Maganaris CN, Baltzopoulos V, Sargeant AJ. In vivo measurement-based estimations of the human Achilles tendon moment arm. Eur J Appl Physiol. 2000;83(4-5):363369 10.1007/s004210000247. PubMed doi:10.1007/ s004210000247

6. Fath F, Blazevich AJ, Waugh CM, Miller SC, Korff T. Direct comparison of in vivo Achilles tendon moment arms obtained from ultrasound and MR scans. J Appl Physiol. 2010;109:1644-1652 10.1152/japplphysiol.00656.2010. PubMed doi:10.1152/japplphysiol.00656.2010

7. An K, Takahashi K, Harrigan TP, Chao EY. Determination of muscle orientations and moment arms. J Biomech Eng. 1984;106(3):280 10.1115/1.3138494. PubMed doi:10.1115/1.3138494

8. Storace A, Wolf B. Functional analysis of the role of the finger tendons. J Biomech. 1979;12(8):575578 10.1016/0021-9290(79)90076-9. PubMed doi:10.1016/0021-9290(79)90076-9

9. Reuleaux F. Theoretische Kinematik: Grundzüge einer Theorie des Maschinewesens. Braunschweig: Vieweg; 1875.

10. Riemann BL, DeMont RG, Ryu K, Lephart SM. The effects of sex, joint angle, and the gastrocnemius muscle on passive ankle joint complex stiffness. J Athl Train. 2001;36(4):369-377. PubMed 
Copyright of Journal of Applied Biomechanics is the property of Human Kinetics Publishers, Inc. and its content may not be copied or emailed to multiple sites or posted to a listserv without the copyright holder's express written permission. However, users may print, download, or email articles for individual use. 